\title{
Assessing the Implementation of Total Quality Management in Education Administration Institutions in Central Province, Sri Lanka
}

\author{
M. W. M. Abeykoon ${ }^{1}$ and Chamaru De Alwis ${ }^{2}$ \\ ${ }^{2}$ Department of Human Resource Management, University of Kelaniya, Sri Lanka \\ ${ }^{1}$ maheshaabeykoon@yahoo.com, ${ }^{2}$ dealwisac@gmail.com
}

\begin{abstract}
The purpose of this study was to assess the implementation of TQM aspects among education administration institutions in the central province, Sri Lanka. This study focused on identifying the level of Hard TQM implementation and Soft TQM implementation among selected education administration institutions. A five point Likert scale questionnaire was used as the key instrument of data collection. The data were obtained from a survey of 41 administrators in education administration institutions in central province. The findings suggest that the level of hard TQM implementation is at a high level and the level of soft TQM implementation is at a moderate level. Further the study reports that the level of hard TQM implementation is higher than the level of soft TQM implementation. Among the studied Hard TQM techniques Quality Circles is reported as the most adopted technique. Customer / Citizen Satisfaction and Top Management Commitment and Support are the top principles adopted among the studied Soft TQM practices. In addition to that, report revealed that there is no significance difference in between districts in central province when implementing hard TQM and soft TQM.
\end{abstract}

Keywords: Total Quality Management, Hard TQM, Soft TQM, Education Administration Institutions, Central Province

\section{Introduction}

In a highly competitive world with increasing consumer demands, quality has become a key factor of survival in the market, of profitability and development, not just for individual sectors and organizations, but also for the whole country's economy. 
Total Quality Management (TQM) initially advocated by Dr. W. Edwards Deming in the late 1950's was originally intended for the industrial sector. Further Deming pointed out in the preface to his book Out of the Crisis that his management principles could be applied equally well in service sectors.

When it comes to the Sri Lankan context in recent past decade it has identified the value of applying TQM concepts in both public and private sector. It is now attracting increasing attention in the field of education.

In Sri Lanka Quality Education is at the base of a country's process of development. It is identified as a necessity to strengthen the quality of the administrative processes. As a result, in 2004 Quality Assurance Unit of Ministry of Education (MOE) has started introducing TQM concepts. Further Quality Assurance Unit has conducted training programs and awareness programs to successfully carryout TQM concepts in education sector.

Now it has passed almost ten years for introducing TQM concepts for education sector after establishing Evaluation and Quality Assurance Unit. Therefore, the purpose of this study is to investigate to what extent TQM (TQM) practices use among education administration institutions in central province, Sri Lanka.

\section{Literature Review}

Lau and Anderson (1998) stated that there are no uniformed definitions of what TQM is. According to Chang (2006) TQM is a theory which emphasizes the understanding of variation; the importance of measurement; the role of internal and external customers and suppliers and the involvement of employees at all levels of an organization in pursuit of continuous improvement.

Wilkinson, (1998) mentioned that, we can look in at the two aspects of the TQM namely 'Hard' and 'Soft' aspects. Review of TQM literature showed that the key elements of TQM could be classified as "ST" and "HT" quality factors. Both the "hard" practices (such as measurement and analysis, systematic planning, fact-based decision making), and the "soft" practices or the humanistic factors- (such as visioning and establishing organization values, recognition of individual and group behavior, empowering workers, teamwork and consensual decision-making) (Khalili \& Subari, 2013) 
The hard aspect involves a range of production techniques including statistical process control, changes in the layout, design processes and procedures of the organization, and use of the seven basic TQM tools used to interpret data. (Process Flow Charting, Tally Charts, Pareto Analysis, Scatter Diagrams, Histograms, Control Charts and Cause and Effect Analysis) (Wickramaratne, 2013).

The "soft" side is associated with management concepts and principles such as leadership, employee empowerment and culture (Psyhogios \& Vouzas, 2007).

The soft side focuses on the management of human resources in the organization and lays particular emphasis on the need to change the culture (Wickramaratne, 2013).

The adoption of "soft" and "hard" TQM elements can lay the foundations for improving the way a company operates and hence its quality.

\section{Conceptual Framework}

The framework adopted in this study is highly influenced by the studies of Psychogias (2007), Imer, Kekale, Takala, Liu (2014) and Yapa (2012). The following conceptual framework was developed to measure the level of implementation of TQM aspects in the education sector Sri Lanka. Following figure 01 shows the conceptual framework of this study. Hard refers to TQM techniques and the soft aspect of TQM refers to the principles of TQM. Here a technique refers to systematic procedure by which a task is accomplished and a principle refers to a rule or standard that is adhered to be. 
Kelaniya Journal of Human Resource Management

Volume 09-Number 01-January 2014 \& Number 02-July 2014

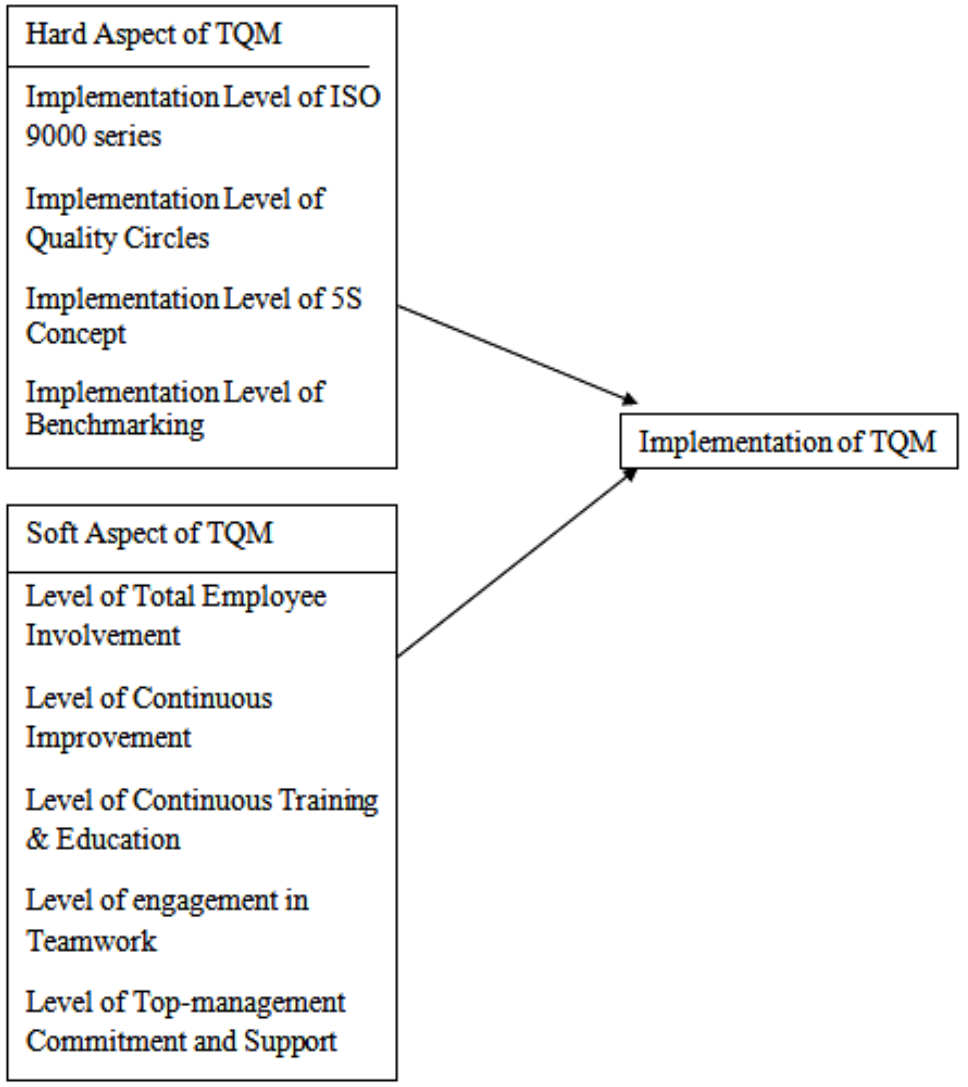

\section{Figure 01: Conceptual Framework}

Source: Psychogias (2007), Imer, Kekale, Takala, Liu (2014) and Yapa (2012)

In this study, hard aspect of TQM Four techniques namely ISO 9000 series, Quality Circles, 5S concept and Benchmarking were the techniques used to measure the implementation level of hard aspect of TQM.

The implementation level of soft aspect of TQM was identified by using seven principles namely Total Employee Involvement, Continuous Improvement, Continuous Training and Education, Teamwork, Top Management Commitment and Support, Customer/ Citizen Satisfaction and Culture Change. 


\section{Hypotheses Development}

According to objectives of the research the following hypothesis was developed to identify which aspect (Hard/Soft) of TQM has the higher TQM adoption.

Objective: To find out which aspect (Hard/Soft) of TQM has the higher implementation among education administration institutions.

H1: Implementation of Hard TQM practices are higher than implementation of soft TQM practices.

\section{Methodology}

Since the main objective of the research was to assess the level of implementation of TQM techniques (hard aspect) and principles (soft aspect) in the education sector Sri Lanka, this research is essentially a survey-based research. In addition to that this study aimed to identify which aspect (Hard/Soft) of TQM has the higher adoption and to identify whether there is a difference between the TQM implementation practices in between districts in the central province.

\subsection{Reliability Test}

Reliability tests were conducted using IBM SPSS version 17.0 to confirm the internal consistency. The Cronbach's Alpha test was used to test the internal consistency of the instruments. Reliability coefficient of .70 or higher is considered "acceptable" in most social science research environments (Creswell, 2002). Based on the results of the reliability test it has found that alpha value of each variable is greater than. 70 which was considered that the items have relatively high internal consistency.

\subsection{Population}

The Population of the study consists of all the education administrative bodies of central province, Sri Lanka. It consists of 15 Zonal Education Offices, and 44 Divisional Education Offices. Altogether population consists of 59 Education Administration Institutions. 


\subsection{Sample}

Sample is selected based on the stratified random sampling. Sample is divide in to strata's based on geographical boundaries, which means strata are identified based on the district. From each strata sample is selected randomly. Sample represents $70 \%$ of the population. And it consists of 41 organizations. The following table illustrates the population and sample information.

Table 01: Sample Composition

\begin{tabular}{|l|l|l|}
\hline \multicolumn{1}{|c|}{ District } & Population & Sample \\
\hline Kandy & 27 & 19 \\
\hline Matale & 15 & 10 \\
\hline Nuwara Eliya & 17 & 12 \\
\hline Total & 59 & 41 \\
\hline
\end{tabular}

Source: Survey Data, 2015

\subsection{Data Collection}

The data was gathered by using both primary and secondary sources. The major data for this study was primary data. Primary data was gathered by using a questionnaire. A five point Likert ordinal scale was employed throughout the questionnaire in order to indicate the degree of agreement or disagreement with each statement included in the questionnaire. Twenty statements were designed to examine the level of TQM implementation with regard to hard TQM aspect. And twenty nine items were used to measure the implementation of soft TQM.

\subsection{Data Analysis}

Data were analyzed using descriptive statistics and inferential statistics. Descriptive statistic tools namely central tendency measures and frequency distribution were used to assess the level of TQM implementation in both hard and soft aspect which is the main objective of the study. To identify which aspect (Hard/Soft) of TQM has the higher adoption hypothesis was developed and it was tested by using the paired sample $t$ test. To identify which aspect of TQM has the higher implementation inferential statistical tools were used. To identify whether there is a difference between the TQM 
implementation in between districts in the central province ANOVA was used.

The developed questionnaire was handed over to 41 education administration offices. However 38 questionnaires were returned. Therefore the response rate of the questionnaire was $92 \%$. The normality of the data set was evaluated by Kolmogorov - Smirnov (K-S) and Shapiro - Wilk (SW) tests. Study sample characterized of 8 Zonal Education Offices (ZEO) and 30 Divisional Education Offices (DEO) from Kandy, Matale and Nuwara Eliya Districts.

\section{Findings}

According to the survey data as a whole, the level of hard TQM implementation can be depicted as following table 02 .

Table 02: Level of Hard TQM Implementation

\begin{tabular}{|l|l|l|}
\hline \multicolumn{1}{|c|}{ Level of Implementation } & \multicolumn{1}{c|}{ Frequency } & \multicolumn{1}{c|}{ Percentage } \\
\hline Low & - & - \\
\hline Moderate & 11 & $28.9 \%$ \\
\hline High & 27 & $71.1 \%$ \\
\hline Total & 38 & $100 \%$ \\
\hline
\end{tabular}

Source: Survey Data, 2015

Accordingly 27 of the institutions (71.1\%) /respondents implements hard TQM at a high level and the rest of the respondents 11 institutions (28.9\%) implements the hard TQM at a moderate level.

In this study four TQM techniques namely ISO 9000 series, 5S concept, Benchmarking and Quality Circles were used to identify the level of hard TQM implementation. Following figure 02 summarizes the percentages of Level of implementation of Hard TQM by Technique. 


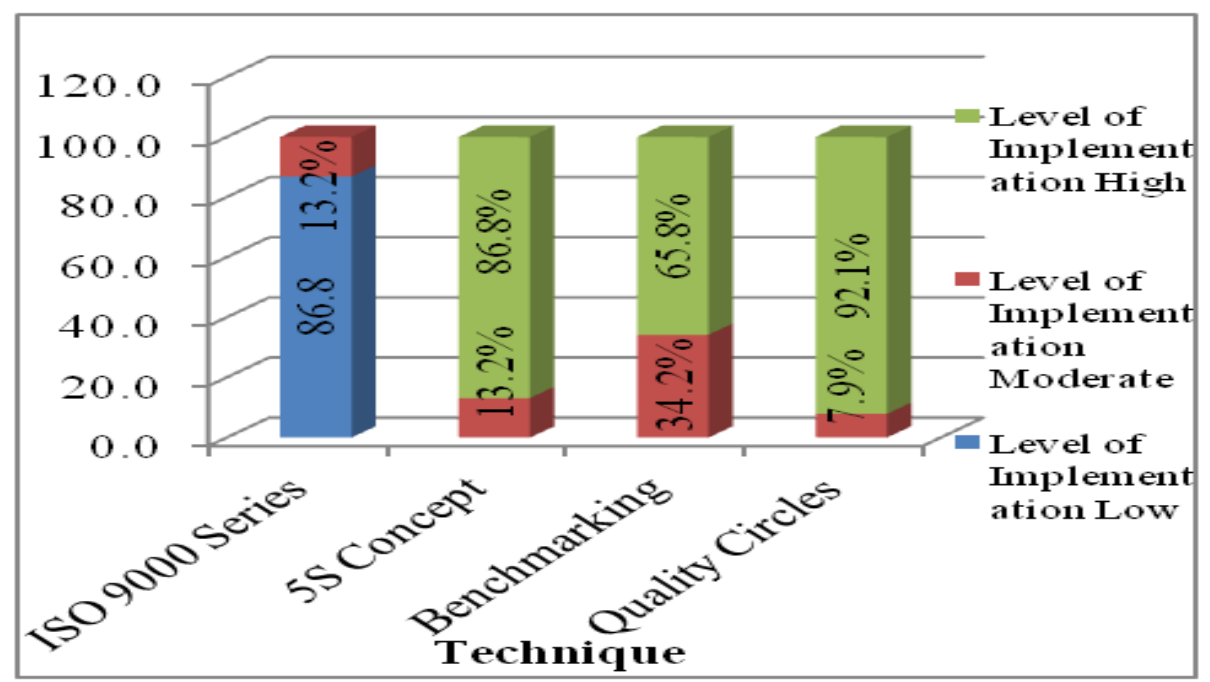

Figure 02: Percentages of Level of Hard TQM by Technique

In the hard TQM aspect level of TQM implementation is different from one technique to another. Implementation level of ISO 9000 series is low and the level of implementation of the techniques namely 5S, Benchmarking and Quality Circles are high.

According to the study data the level of soft TQM implementation is as following Table 03. Accordingly, 24 (63.2\%) of the respondents implements soft TQM at a moderate level and $14(36.8 \%)$ of the respondents implements soft TQM at a high level.

Table 03: Level of Soft TQM Implementation

\begin{tabular}{|l|l|l|}
\hline Level of Implementation & Frequency & Percentage \\
\hline Moderate & 24 & $63.2 \%$ \\
\hline High & 14 & $36.8 \%$ \\
\hline Total & 38 & $100 \%$ \\
\hline
\end{tabular}

Source: Survey Data, 2015

Following figure 03 presents the level of implementation of Soft TQM practices among Education Administration Institutions in Central Province. 


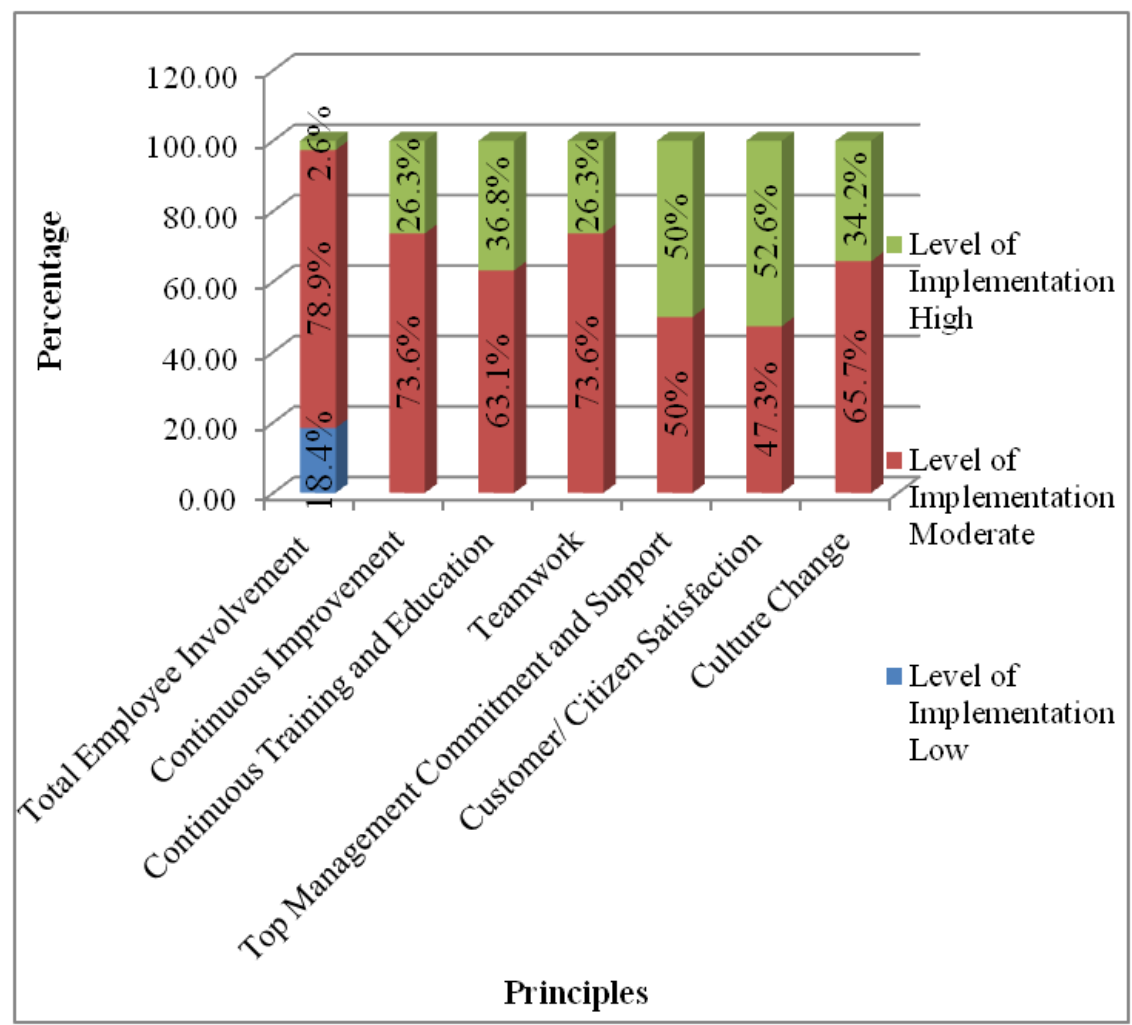

\section{Figure 03: Level of implementation of Soft TQM practices}

Implementation level of the principles namely total employee involvement, continuous improvement, continuous training and education, teamwork and culture change is moderate and the level of customer satisfaction is high.

Findings of the research proved that the level of TQM implementation in both soft and hard aspects of TQM in central province education administrative institutions is vary from low level to high level.

A paired-samples t-test was conducted to compare the level of Hard TQM implementation and the level of Soft TQM. There was a statistically significant difference in the scores for the level of Hard TQM implementation $(\mathrm{M}=3.71, \mathrm{SD}=0.46)$ and the level of Soft TQM implementation $(\mathrm{M}=3.37, \mathrm{SD}=0.489)$ conditions; $\mathrm{t}(37)=3.95, \mathrm{P}=0.0002$ (one tailed). 
Therefore based on the results of the paired sample $t$ test $(\mathrm{p}=0.0005)$ at the confidence level of $95 \%(p<0.05)$ rejected the null hypothesis. Hence, accepted the alternative hypothesis. Therefore the results suggested that the level of implementation of Hard TQM is higher than the level of implementation of Soft TQM.

To identify whether there is a difference between the TQM implementation, techniques (hard TQM) and principles (Soft TQM) adopted in each district in central province one way ANOVA has used.

The test of homogeneity of variance was assumed based on the results of Levene's test as in the HTQM P=0.681 and in the STQM P $=0.354$ at the 0.05 alpha level.

Following ANOVA table 04 shows the output of the ANOVA analysis.

Table 04: ANOVA

\begin{tabular}{|l|l|l|l|l|l|l|}
\hline & \multicolumn{1}{|c|}{$\begin{array}{c}\text { Sum of } \\
\text { Squares }\end{array}$} & df & $\begin{array}{c}\text { Mean } \\
\text { Square }\end{array}$ & F & Sig. \\
\hline HTQM & $\begin{array}{l}\text { Between } \\
\text { Groups } \\
\text { Within } \\
\text { Groups } \\
\text { Total }\end{array}$ & 1.960 & 2 & .980 & .048 & .953 \\
\hline STQM & $\begin{array}{l}\text { Between } \\
\text { Groups } \\
\text { Within } \\
\text { Groups } \\
\text { Total }\end{array}$ & 155.735 & 2 & 77.867 & 1.824 & .176 \\
\hline
\end{tabular}

Source: Survey Data, 2015

As per the table sig value of the HTQM is 0.953 ( $\mathrm{p}=0.953$ ) which is greater than 0.05 and therefore there is no statistically significant difference in the mean of HTQM in each district. Therefore it can be concluded that there is no any significant difference between districts when implementing hard TQM. 
When attempting on STQM the sig value is $0.176(\mathrm{p}=0.176)$ is greater than 0.05 . Therefore there is no statistically significant difference in the mean of STQM in each district. Therefore it can be concluded that there is no any significant difference between districts when implementing soft TQM.

\section{Discussion}

Findings of the research proved that the level of TQM implementation in both soft and hard aspects of TQM in central province education administrative institutions is vary from low level to high level. The level of TQM implementation is differing from hard TQM to soft TQM. According to the findings $71.1 \%$ of the institutions implement hard TQM techniques at a high level and $28.9 \%$ at a moderate level. With regard to the soft TQM $63.2 \%$ of the institutions implement soft TQM principles at a moderate level and $36.8 \%$ at a high level.

Even in the hard TQM aspect level of TQM implementation is different from one technique to another. In this study four TQM techniques namely ISO 9000 series, 5S concept, Benchmarking and Quality Circles were used to identify the level of hard TQM implementation. As mentioned above each of these techniques implements at different levels ranging from low level to high level.

When consider the technique ISO 9000 series majority (86.84\%) of the institutions apply ISO 9000 series at a low level and the minority (13.16\%) at a moderate level. According to a research done by Yapa (2012) on TQM adoption in service sector in Sri Lanka, revealed that only 32 per cent of the organizations in the selected sample have obtained the ISO certificate. As per the current study also it revealed that the level of ISO 9000 series is implementing at a low level. As a percentage $13.16 \%$ of the studied institutions implement ISO at a moderate level. Therefore it is consistent with the findings of the previous research done by Yapa (2012).

According to the findings of a research done by Longo (1997) regarding the Total Quality Management in the financial services of United Kingdom (UK) and Brazil, found that in terms of quality initiatives in the UK organizations were using many programmes to improve quality such as Quality Standards (ISO 9000/ BS 5750). Further it revealed Brazilian organizations were relying on investing heavily in ISO 9000 credentials). 
Further this study revealed that the most used conceptual models in these countries are the Five Gaps Model, Japanese 5-S and ISO 9000. But the present study, although the sector is different findings are inconsistent when comparing the findings of Longo, 1997. Because in Sri Lankan education sector institutions ISO 9000 series is applying at a low level.

With regard to the $5 \mathrm{~S}$ concept majority (86.8\%) of the institutions apply $5 \mathrm{~S}$ at a high level and minority (13.2\%) at a moderate level. According to a research done by Kaluarachchi (2009) regarding the successful TQM implementation in Sri Lankan public hospitals revealed that the implementation of $5 \mathrm{~S}$ is successful in hospitals, which shows the application of $5 \mathrm{~S}$ in health sector in Sri Lanka. The finding of the present research also proves that the $5 \mathrm{~S}$ concept is even applying in the education sector as well. Therefore the finding of the research is compatible with the previous research done by Kaluarachchi (2009) although the sector is different.

When comparing the findings of the present study with the findings of the Longo (1997) it is consistent. As in the studied education administration institutions in central province, the application of $5 \mathrm{~S}$ concept is high, as well as according to the findings of the Longo, it is one of the most used model in the financial sector in UK and Brazil.

The level of implementation with regard to the benchmarking is as majority (65.8\%) of the institutions implementing benchmarking at a high level and minority $(34.2 \%)$ at a moderate level. Findings of the study, proves that the level of implementation of benchmarking is at a high level and as a percentage it is $65.8 \%$. This finding is consistent with the previous research findings by Yapa (2012) as in that study 57\% of the selected service sector institutions implementing benchmarking.

According to the findings of a research done by Longo (1997) regarding the Total Quality Management in the financial services of United Kingdom (UK) and Brazil, found that in terms of quality initiatives in the UK organizations, were using many programmes to improve quality such as, Competitive Benchmarking. Although the sector is different in the studies, above mentioned findings of Longo is consistent with the present study as in both country context benchmarking is highly applying. 
When considering the quality circles majority (92.1\%) of the institutions implement QC at a high level and the minority (7.9\%) at a low level. The findings of the present study regarding the QC is incompatible with the findings of the previous study done by Yapa (2012). In the previous study it revealed that the $44 \%$ of the institutions subjected to the study implements QC. Current study revealed that $92 \%$ of the selected sample implements QC.

As well as in the level of soft TQM implementation the selected TQM principle's implementation levels are different from one another. In this study seven TQM principles were used to measure the level of soft TQM namely total employee involvement, continuous improvement, continuous training and education, teamwork, top management commitment and support, customer/ citizen satisfaction and culture change. As same as the hard TQM techniques, each of above mentioned TQM principles are differ from each other in according to their implementation level.

In view of that, majority (78.95\%) implement total employee involvement at a moderate level and minority $(21.05 \%)$ at low and high levels. The findings of the study, regarding the total employee involvement is compatible with the findings of Yapa (2012). According to findings of the Yapa 80\% of the institutions subjected to his study implements the principle total employee involvement. The current study further confirms this due to the $78.95 \%$ of the selected sample implements total employee involvement at a moderate level.

With regard to continuous improvement majority (73.7\%) implement continuous improvement at a moderate level and minority (26.3\%) implements at a moderate level. When considering the level of continuous training and education majority (63.2\%) of the institutions apply continuous training and education at a moderate level and the minority (36.8\%) at a high level. With respect to teamwork the level of implementation lies with majority $(73.7 \%)$ at a moderate level and the minority (26.3\%) at a high level.

When taking into consideration, the level of top management commitment and support $50 \%$ of the institutions have a moderate level of top management commitment and support and the other 50\% have a high level of top management commitment and support. According to the findings of a 
previous research done by Yapa (2012) Top management commitment, one of the pre-requisites for a successful implementation is good among the selected organizations. This study reveals that the top management commitment and support is at a good level as the half of the selected institutions adopt top management commitment and support at a high level and rest half of the institutions at a moderate level. Therefore the finding of the current study is consistent with the previous studies in the context.

Further majority (52.6\%) of the institutions apply the TQM principle customer satisfaction at a high level and the rest minority (47.4\%) at a low level. According to the findings it depict that the majority $(65.8 \%)$ of the institutions apply culture change at a moderate level and the minority (34.2\%) at a high level.

According to a research done by Kaluarachchi (2009) regarding the successful TQM implementation in Sri Lankan public hospitals with reference to the Castle Street Hospital for Women in Sri Lanka, revealed that the change of culture, leadership, teamwork and employee involvement were the factors behind the successful implementation of TQM which implies that these principles are implementing in public hospitals. Even though the sector is different findings of the present research is consistent with the findings of the Kaluarachchi (2009). Accordingly change of culture, leadership, teamwork and employee involvement implement in the education sector as well, based on the findings of the research.

In addition to that the results of the survey prove that the level of implementation of hard TQM is higher than the level of implementation of soft TQM among the education administration institutions in the central province.

Further this study reveals that there is no significance difference between the districts in central province when implementing TQM in both aspects of TQM as hard TQM and soft TQM.

\section{Conclusion}

Based on the findings of the study it can be conclude that the level of TQM implementation with regard to hard and soft aspect is different. There by findings proves that the level of hard TQM implementation is higher than the level of soft TQM implementation. In hard TQM aspect, majority of the 
institution implements hard TQM techniques at a high level. But in the soft TQM aspect, majority of the institutions implements soft TQM principles at a moderate level. Further the findings showed that, in the hard TQM minority implements hard TQM techniques at a moderate level but in soft TQM minority implements soft TQM principles at high level. This shows the difference between the hard and soft TQM implementation levels and therefore the conclusion is that the level of hard TQM implementation is higher than the soft TQM implementation.

With regard to the hard TQM techniques it can be conclude that implementation level of ISO 9000 series is low and the level of implementation of the techniques namely 5S, Benchmarking and Quality Circles are high.

By and large it can be concluded that the implementation level of the principles namely total employee involvement, continuous improvement, continuous training and education, teamwork and culture change is moderate and the level of customer satisfaction is high. The level of top management support and commitment is neither high nor moderate.

Further based on the findings this study confirms that there is no significant difference in between the districts of central province when implementing TQM techniques and principles.

\section{Recommendations}

In accordance with the findings and the conclusions it is recommended to increase the implementation of the soft TQM practices. As per the findings of Rahman and Bullock (2005) successful organizations are those that apply a combination of Soft TQM and Hard TQM policies to respond to changing customer requirements. Therefore responsible parties of these education administration institutions should concern more about the soft TQM practices.

Accordingly following suggestions can be recommended regarding the implementation of both hard and soft aspects of TQM.

In the majority of the institutions hard TQM practices are implements at a higher level; therefore it is recommended to maintain those practices in the 
future as well. Further the recommendations are made to increase the hard TQM practices in the institutions those who currently implement hard TQM at a moderate level.

In addition to that it is suggested that minority of the institutions those who implement soft TQM practices at a high level should maintain their practices for long term and the institutions those who implement soft TQM at a moderate level should concern more on increasing the soft TQM practices.

With regard to the hard TQM techniques implementation level of ISO 9000 series is low and it is recommended make initiatives to adopt this technique. Further level of implementation of the techniques namely 5S, Benchmarking and Quality Circles are high and it is recommended to maintain those practices for the long term.

Moreover it is recommended to increase the adoption of the soft TQM practices in the facet of total employee involvement, continuous improvement, continuous training and education, teamwork and culture change. In addition to that more concern should be made on the top management commitment and support. And it is suggested that the existing level of customer satisfaction should be maintained and should be further increased.

\section{References}

Chang, H. H. (2006). An empirical evaluation of performance measurement systems for total quality management. Total Quality Management, 17(8), 1093-1109.

Imeri, S., Kekäle, T., Takala, J., \& Liu, Y. (2014). Understanding the impact of 'hard'and 'soft'elements of TQM in south-east European firms. Management and Production Engineering Review, 5(3), 9-13

Kaluarachchi, S. P. (2009). Successful TQM implementation in Sri Lankan public hospitals. Annals of business administrative science, 8(0), 5574. 
Khalili, A. A., \& Subari K. (2013). Understanding the Linkage between Soft and Hard Total Quality Management: Evidence from Malaysian Manufacturing Industries. Jordan Journal of Mechanical and Industrial Engineering, 7 (1), 57-65.

Lau, R. S., \& Anderson, C. A. (1998). A three-dimensional perspective of total quality management. International Journal of Quality \& Reliability Management, 15(1), 85-98.

Longo, C. R. J. (1997). An assessment of Total Quality Management in the financial services of United Kingdom and Brazil: a framework for implementation is proposed employing Quality Function Deployment

Psychogios, A.,\& Vouzas, F. (2007). Assessing Manager's Awareness of

TQM. The TQM Magazine, 62-75.

Rahman, S. U., \& Bullock, P. (2005). Soft TQM, hard TQM, and organizational performance relationships: an empirical investigation. Omega, 33(1), 73-83.

Taleghani, M., Mousavian, S. J., \& Choobeh, E. R. (2011). The role of total quality management in performance improvement of new enterprises (Case study: Insurance industries of northern Iran). Interdisciplinary Journal of Contemporary Research in Business, 3(6), 35.

Wickramaratne, W. R. (2013). Leadership and TQM Excellence: Empirical Study of ISO Certified Manufacturing Firms in Sri Lanka. International Journal of Arts and Commerce, 2(9).

Wilkinson, A. (1998) "Empowerment: theory and practice" Personnel Review.Vol.27, No. 1, 40-56.

Yapa,S.(2012). Total quality management in Sri Lankan service organizations. The TQM Journal, 24(6), 505-517. 